\title{
Evaluation of Injection Molding Process Parameters for Manufacturing Polyethylene Terephthalate
}

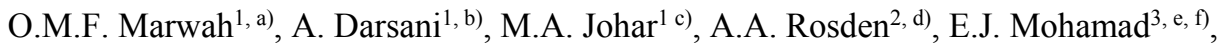 \\ M.F. Shaari ${ }^{1, g}$, R.H.A. Haq ${ }^{1}$, A.M. Amin ${ }^{1}$ \\ ${ }^{1}$ Department of Manufacturing and Industrial Engineering, Faculty of Mechanical and Manufacturing \\ Engineering, Universiti Tun Hussein Onn Malaysia, 86400 Johor, Malaysia. \\ ${ }^{2}$ Nilai Legasi Plastik Sdn. Bhd. Jalan P/AM 3, Desaria, 71800 Nilai, Negeri Sembilan. \\ ${ }^{3}$ Department of Mechatronics and Robotics Engineering, Faculty of Electrical and Electronic \\ Engineering, Universiti Tun Hussein Onn Malaysia, 86400Johor, Malaysia
}

\begin{abstract}
Quality control is an important aspect in manufacturing process. The quality of product in injection moulding is influenced by injection moulding process parameter. In this study, the effect of injection moulding parameter on defects quantity of PET preform was investigated. Optimizing the parameter of injection moulding process is critical to enhance productivity where parameters must operate at an optimum level for an acceptable performance. Design of Experiment (DOE) by factorial design approach was used to find an optimum parameter setting and reduce the defects. In this case study, Minitab 17 software was used to analyses the data. The selected input parameters were mould hot runner temperature, water cooling chiller temperature 1 and water cooling chiller temperature 2. Meanwhile, the output for the process was defects quantity of the preform. The relationship between input and output of the process was analyzed using regression method and Analysis of Variance (ANOVA). In order to interpolate the experiment data, mathematical modeling was used which consists of different types of regression equation. Next, from the model, 95\% confidence level ( $p$-value) was considered and the significant parameter was figured out. This study involved a collaboration with a preform injection moulding company which was Nilai Legasi Plastik Sdn Bhd. The collaboration enabled the researchers to collect the data and also help the company to improve the quality of its production. The results of the study showed that the optimum parameter setting that could reduce the defect quantity of preform was $\mathrm{MHR}=88^{\circ} \mathrm{C}, \mathrm{CT} 1=24^{\circ} \mathrm{C}$ and $\mathrm{CT} 2=27^{\circ} \mathrm{C}$. The comparison defect quantity analysis between current companies setting with the optimum setting showed improvement by $21 \%$ reduction of defect quantity at the optimum setting. Finally, from the optimization plot, the validation error between the prediction value and experiment was $1.72 \%$. The result proved that quality of products can be improved by using the DOE approach.
\end{abstract}

*Corresponding author: mdfaizan@uthm.edu.my 


\section{Introduction}

Plastic manufacturing has been one of the competitive markets which make producers to produce high quality parts at a low price and within the least time [1]. This study focused on the production of plastic PET preform which are produced in large volumes. A mandatory process involved in this production is injection moulding. Injection moulding is a standard method for producing parts in a large number and with high quality, value added commercial or industrial plastic parts in the market [2].

Polyethylene terephthalate (PET) belongs to a group of materials known as thermoplastic polymer of which would become softened and deformed due to heat.. PET is one of the materials suitable to be used in plastic industries especially to make bottle preform [3]. The preforms produced using this material have some advantages such as impact resistant, very lightweight and non-toxic when in contact with food [4].

In the industrial field, the quality and quantity of production are two important matters. Nilai Legasi Plastik Sdn Bhd (NLP) is one of the companies that manufactures preform products by using injection moulding process. Based on an observation, the company uses trial and error method to have set the moulding parameter to get the best quality of production. Unfortunately, there were moulding defects that have occurred in the production of the perform, Incorrect input parameters settings has caused bad defects and increased production cost. Therefore, finding an optimized parameters is highly desirable [5]. A collaboration between UTHM and NLP has opened up an opportunity to conduct this study. In order to produce good quality parts, the optimized moulding parameter based on DOE approach is suggested for the processes of plastic preform

Design of Experiment (DOE) is one of the many problem solving or improvement quality tools that can be used for various investigations such as finding the significant factor in a process, the effect of each factor on an outcome and screening a parameter. Many industries use this tool to stay competitive worldwide by designing robust products as well as improving their quality and reliability. [6]. One of the methods under DOE is factorial design method. Generally, factorial design is the most efficient method to be used in an experiment where the study of effects of two or more factors are involved [11]. The effect of factor is defined as the change in response, produced by a change in the level of the factor. The model of process and optimal condition are developed using analytic methods and heuristic algorithms [7]. Most researchers have considered mould temperature as a very important parameter. A module called Mould Temperature Controller (MTC) is used to control mould temperature. The MTC is very expensive and generally not incorporated in a basic control system. This constraints the effective control of the output of injection moulding. In the absence of MTC, optimization of process parameters can be achieved by considering the coolant flow rate along with other process parameters [8]. At NLP, there is an MTC machine which is called as Mould Hot Runner Temperature Controller. In this study, the temperature on Mould Hot Runner Temperature Controller and Water Cooling Temperature machine was strictly controlled. Moreover, the experiment and the analysis was designed by using the Minitab Software.

Finally, from this study, it was expected that the best analysis of process parameter optimization for the production of PET preform injection moulding process at the NLP by using DOE approach would be obtained.

\section{Literature Review}

Injection moulding is one of the popular manufacturing processes among the plastic industries. For this study, the application of injection moulding process was specifically 
conducted for the manufacturing of PET preforms and PET bottles. Fig.1 shows the specific injection moulding process for preforms., It started with the PET granulates are fed into the hopper (1). Then, the granules will traverse from the hopper using gravity into a heated barrel $(2,3)$ and crushed via a rotating screw into a molten form. The heated liquid plastic has a temperature in between $250{ }^{\circ} \mathrm{C}$ to $320^{\circ} \mathrm{C}(\mathrm{PET})$. The screw propels the molten plastic through a nozzle (4) into a two sided mould (5) which defines the shape of the preform. When the mould (5) is filled with the pre-programmed amount of the molten plastic, it is closed by the hydraulic clamp force (6) which is generated by an electric motor and a hydraulic pump (7). The mould will be hold together by the clamp within the time period which is needed for the products to cool down. The mould is cooled with external water cooling during the process to ensure that the preform solidifies fast and becomes as homogenous as possible. After cooling down, the end products are ejected from the mould by an ejector pin (8) which pushes the preform out of the mould. The mould is then reopened and filled using molten plastic that is fed constantly through the hopper and the traversing screw [4].

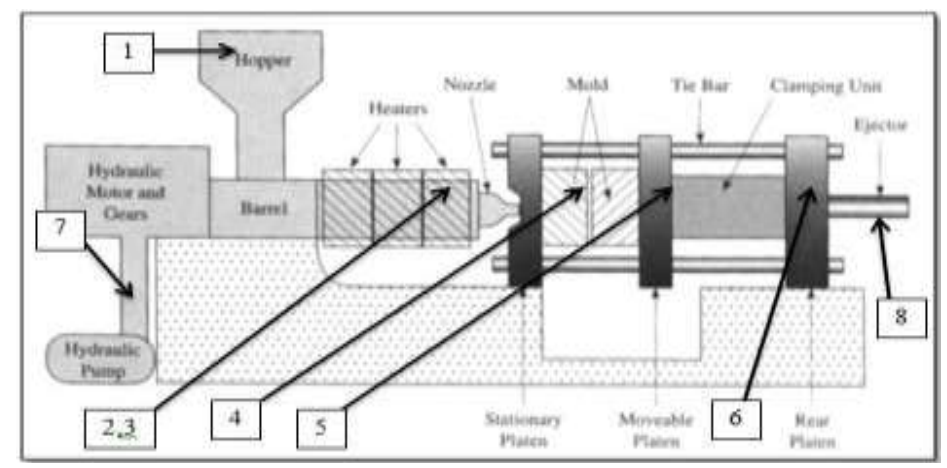

Fig. 1. Diagram of injection moulding machine process

In addition, 16 cavities preforms mould use the hot runner system rather than cold runner system. As such, the design of hot runner system plays an important role in guaranteeing mould quality. Based on foreign advanced techniques and combined with domestic clients' demand, the valve gated is designed, in which each cavity has its own heating zone and temperature is measured by an independent thermocouple. The advantage of this system is it easily avoids some problems such as white or draw bench at the bottom [8].

Lastly, there are three important things in PET preform processing which are [9]:

- Dry and dehumidify PET material which will be process by autoloader, hopper dryer $\&$ dehumidifier.

- Melting PET material into preform mould by PET injection moulding machine.

- PET preform cooled down and formed in the preform mould which can be controlled by hot runner temperature controller, water cooling chiller controller and cooling water tower.

\subsection{Polyethylene Terephthalate (PET) Preforms}

There is probably no subject in the PET industry shrouded in more secret problem than the design of preforms. There is no handbook, no course, and very little other material that 
prospective preforms designer may peruse to get prepared for the job. The main reason is that preforms design is still without a calculation or simulation that can guarantee a perfectly suitable preforms for a given bottle design and blow machine. This unpredictable factor is due to the problem that the formation of a bottle from a preform is literally explosive and even very tiny temperature variations could affect the outcome. In addition, the particular preform is manifold, still too many to make perfect predictions [3]. Figure 2.2 show the example of PET preforms product.

Based on the literature review in previous research, reference books and articles, there have been no calculation or simulation that could guarantee a perfect preform for a given bottle design and blow machine. However, the quality of the preform can be controlled, depending on the setting of the injection moulding machine used by the industry and condition of the industry. This is because, the process of making preform is very sensitive even for a simple product. PET preforms start to absorb humidity almost immediately after being manufactured by the injection moulding.

There are two methods in making the PET bottles which are "One-Step hot preform method" and "Two-Step cold preform method". One step method is a direct process from PET granule to finished bottles completed in one integrated machine. In this process, the injection moulded preform is withdrawn from the injection cavity while it still hot enough to be stretched and blown to form the bottles. On the other hand, in the two step methods, two separate machines are used. The first one is injection moulding machine that is used for making PET preforms. The other one is the blow moulding machine that is used to reheat the cold preform and then blow it to form the bottles [4]. Actually, there are some defects could happen to the preforms during their production. However, not all preforms have similar defects. Watermarks, shrinkage, burning, bubbles and scratch surface are some examples of defects to PET preforms [10].

\section{Design of Experiment}

Design of Experiments (DOE) is employed for screening the process parameters for the specific mould geometry. Moreover, the DOE is mainly used for checking the important level of each process parameter and quality indicator [6]. There has been a great need to seek quick and effective solutions, especially for glob- al optimal process parameter settings, and the determination of the optimal parameter setting is now recognized as a crucial step if the quality of plastic injection moulding products is to be improved [12]. The basic procedure is to perform a series of well-planned experiments with different settings of a set of variables. This is followed by an analysis of, the corresponding results to gain as much information as possible [2]. A well designed experiment is important because the result and conclusion that can be drawn from the experiment depend to a large extent on the manner how the data are collected.

Many experiments involved the study of the effects of two or more factors. In general, factorial designs are most efficient for this type of experiment. By using the factorial design, each complete trial or replication of the experiment, all possible combinations of the levels of the factors are investigated. For an example, if there are , ${ }^{\text {ee }}$ levels of factor A and „, $\mathrm{b}^{\text {ee }}$ levels of factor $\mathrm{B}$, each replication contains all treatment combinations. When factors are arranged according to the factorial design, the factors are often said to be crossed. The effect of a factor is defined as the change in response to a change in the level of the factor. This is frequently called the main effect because it refers to the primary factors of interest in the experiment [11]. 


\section{Methodology}

\subsection{Specification of Machine and Material}

WY Preform Injection Moulding Machine was used in this study. Meanwhile, other machines including mould hot runner temperature controller, water cooling chiller controller and hopper were supplied by the other companies. The injection moulding machine has 16 cavities that produces 16 preforms in each shot. The mould hot runner temperature controller helps to control the runner for each cavity. This runner temperature is one of the factors that was controlled in this study. Next, two water cooling chiller controllers control the core and cavity of the mould directly and it is one of the other factors that affect the production. The raw material used in this company is PET which was supplied by Recron Malaysia Sdn. Bhd. The material used is of grade A quality with lot number 6868. The net weight for one packaging for this raw material is $1100 \mathrm{kgs}$.

\subsection{Design of Experiment (DOE) for PET Preform}

For this study, in order to identify the input factor and response, the data were collected from the NLP. As the study needed observations on the preform injection moulding process in the company, several time was spent on conducting the observations. By collaborating with NLP, this study was limited to control only the other machines such as mould hot runner temperature controller, water cooling chiller, hopper or tower tank. This was because, the owner of the company wanted to avoid any critical setting that could affect their injection moulding machine especially as the mould has a high maintenance cost. Moreover injection moulding machine is also a very sensitive machine. The company does not want to take any risk of damaging it.

A table form was prepared in order to make the analysis simpler. The data collected from the analysis were recorded in the form which was later keyed in the software. So, after collecting all the data for the parameter involved, the information is put in the Table 1.

Table 1. Details of parameter

\begin{tabular}{|c|c|c|c|}
\hline \multirow{2}{*}{ Parameters } & \multicolumn{3}{|c|}{ Temperature Level $\left({ }^{\circ} \mathrm{C}\right)$} \\
\cline { 2 - 4 } & Low & $\begin{array}{c}\text { Center } \\
\text { Point }\end{array}$ & High \\
\hline $\begin{array}{c}\text { Mould hot runner } \\
\text { controller (MHR) }\end{array}$ & 85 & 88 & 90 \\
\hline $\begin{array}{c}\text { Water cooling chiller } \\
\text { series 1 (CT 1) }\end{array}$ & 23 & 24 & 25 \\
\hline $\begin{array}{c}\text { Water cooling chiller } \\
\text { series 2 (CT 2) }\end{array}$ & 25 & 27 & 28 \\
\hline
\end{tabular}




\section{Results and Discussions}

After the experiment was carried out, the analysis was done using in the Minitab Software. The defect quantity was added in the response column. The defect quantity was calculated based on the experiment production. The total quantity for each run order were 16 cavities $\mathrm{x} 10$ shots $=160$ pieces. Table 2 shows the details information of defect quantity results.

\subsection{Main Effect and ANOVA Table}

The graph of mean effects for defect quantity is shown in Fig. 2. The analysis shows the main effects which are Mould Hot Runner (MHR), Water Cooling Temperature (CT1) and Water Cooling Temperature 2 (CT2). The graph shows, the values of mean scores of each main effect while the low value of mean shows the best value of setting for the effects. For the MHR, CT1 and CT2, the data mean scores recorded were $88^{\circ} \mathrm{C}, 24^{\circ} \mathrm{C}$ and $27^{\circ} \mathrm{C}$ respectively were in low value of mean. The main effects were analyzed as significant where the P-value was 0.000. In the ANOVA, if the p-value is less than 0.05, the variables have statistically significant results. So this proved that the variables are important to be controlled and interaction between them also showed significant $\mathrm{p}$-value.

Then, R-Sq from the table shows almost high percentage value which was $99.85 \%$. The R$\mathrm{Sq}$ indicates the percentage of variation in the response and this shows how fit the variables are in this data. The higher the percentage of R-Sq the better the variables fit in the data. The percentage indicated that all the variables were important and mostly affected the response.

Table 2. Experiment Result

\begin{tabular}{|c|c|c|c|c|c|}
\hline Run Order & Center Pt & MHR & CT1 & CT2 & $\begin{array}{c}\text { Defect } \\
\text { Quantity }\end{array}$ \\
\hline 1 & 1 & 85 & 25 & 28 & 110 \\
\hline 2 & 1 & 85 & 23 & 25 & 96 \\
\hline 3 & 1 & 85 & 23 & 25 & 96 \\
\hline 4 & 1 & 85 & 23 & 28 & 92 \\
\hline 5 & 1 & 90 & 23 & 28 & 100 \\
\hline 6 & 1 & 85 & 23 & 28 & 92 \\
\hline 7 & 1 & 90 & 25 & 25 & 95 \\
\hline 8 & 1 & 90 & 25 & 28 & 91 \\
\hline 9 & 1 & 85 & 25 & 28 & 110 \\
\hline 10 & 1 & 85 & 25 & 28 & 110 \\
\hline 11 & 1 & 90 & 23 & 25 & 80 \\
\hline 12 & 1 & 85 & 23 & 28 & 92 \\
\hline 13 & 1 & 90 & 23 & 28 & 100 \\
\hline 14 & 1 & 90 & 25 & 25 & 95 \\
\hline 15 & 1 & 85 & 23 & 25 & 92 \\
\hline 16 & 0 & 88 & 24 & 27 & 57 \\
\hline 17 & 1 & 90 & 25 & 25 & 95 \\
\hline 18 & 1 & 85 & 25 & 25 & 117 \\
\hline 19 & 1 & 85 & 25 & 25 & 117 \\
\hline 20 & 1 & 90 & 23 & 25 & 80 \\
\hline
\end{tabular}




\begin{tabular}{|c|c|c|c|c|c|}
\hline 21 & 1 & 90 & 25 & 28 & 91 \\
\hline 22 & 1 & 85 & 25 & 25 & 117 \\
\hline 23 & 1 & 90 & 25 & 28 & 91 \\
\hline 24 & 1 & 90 & 23 & 25 & 80 \\
\hline 25 & 0 & 88 & 24 & 27 & 57 \\
\hline 26 & 0 & 88 & 24 & 27 & 57 \\
\hline 27 & 1 & 90 & 23 & 28 & 100 \\
\hline
\end{tabular}

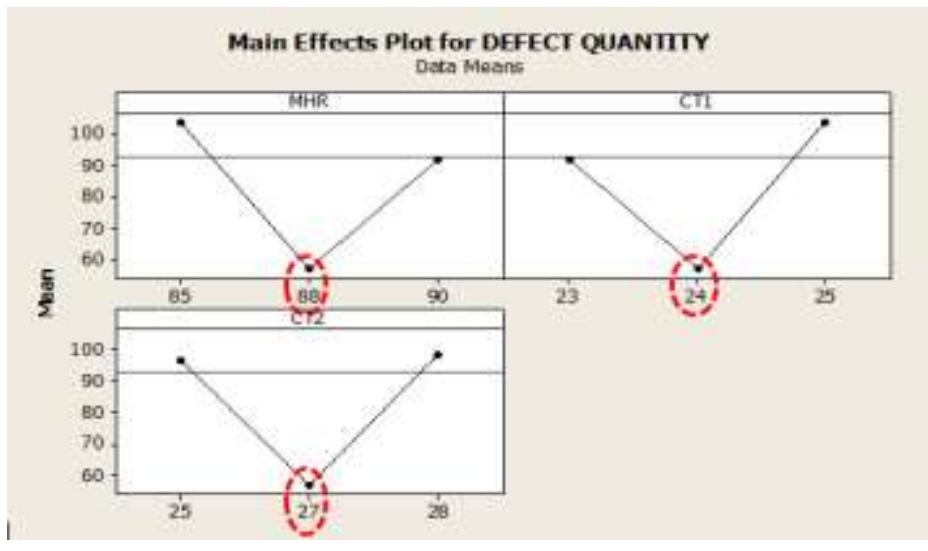

Fig. 2. Main effect plot for injection mould process parameters

\subsection{Analysis of Variance (ANOVA)}

The main effects are concluded as significant where the P-value was 0.000. In the ANOVA, if the $\mathrm{p}$-value is less than 0.05 , it shows that the variables are statistically significant result. So this proved that the variables are important to be controlled and interaction between them also showed the significant p-value. Then, R-Sq from the Fig. 3 shows almost high percentage value which was $99.85 \%$. The $\mathrm{R}-\mathrm{Sq}$ indicates the percentage of variation in the response and this is show how fit the variables are in this data. The higher the percentage of $\mathrm{R}-\mathrm{Sq}$ the better the variables fit in the data. The percentage indicated that all the variables were important and mostly affected the response. Based on ANOVA table in the Minitab, the prediction value of the defect quantity could be identified. By inserting the value of the related factor in this experiment, the prediction of defect quantity could be calculated. Furthermore, from the ANOVA table analysis, the regression equation could be made based on the information of estimated coefficient using data in un-coded units. 


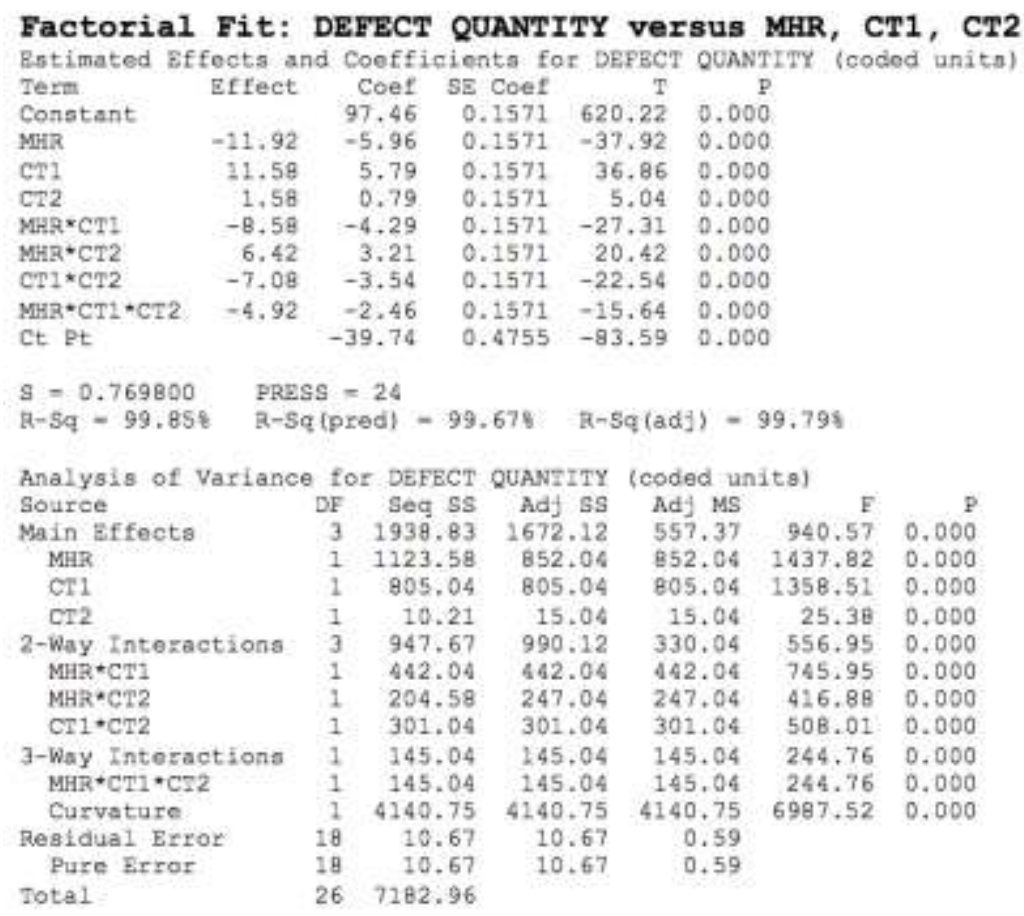

Fig. 3. ANOVA for injection mould process

Moreover, the comparison for defect quantity was made for the three settings which were low and high value of MHR with constant value of CT1 and CT2 and the optimum setting. Fig. 4 shows the comparisons among them.

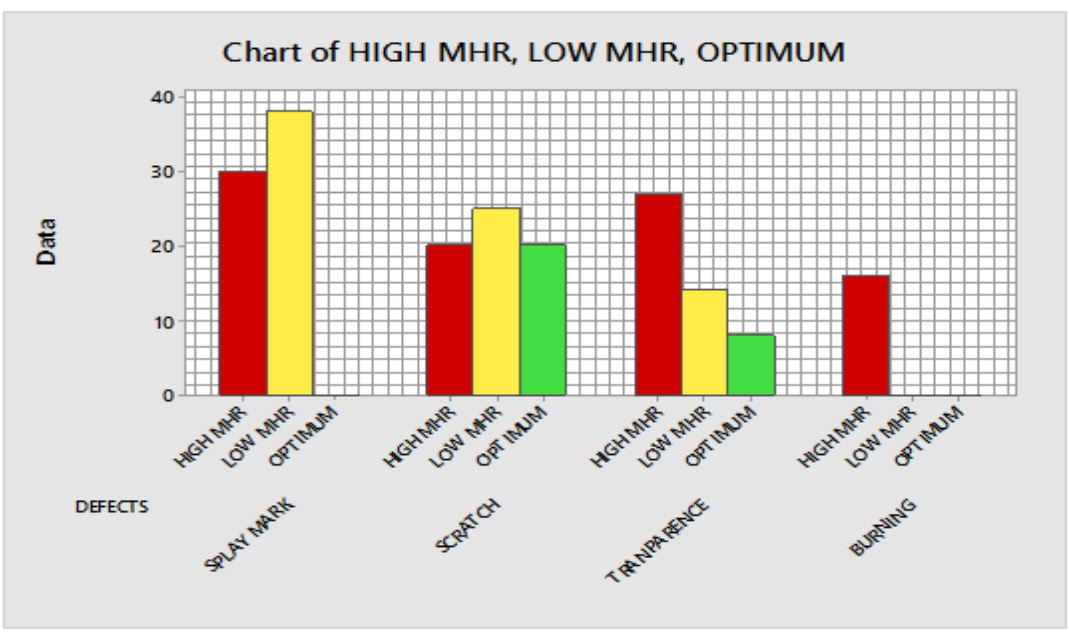

Fig.4. Defect quantity for comparison setting

Finally, based on the regression and graphical analysis, the best setting that showed the less defect quantity was 57 that came from the run order 25, 26 and 27. In this run order, the temperature of mould hot runner temperature, water cooling chiller series 1 and water cooling chiller series 2 were $88^{\circ} \mathrm{C}, 24^{\circ} \mathrm{C}$ and $27^{\circ} \mathrm{C}$ respectively. In order to show that this setting is much better than the setting that was used in the company, the experiment also run for that current setting which the mould hot runner temperature was $90^{\circ} \mathrm{C}$, water cooling chiller 1 was $26^{\circ} \mathrm{C}$ and water cooling chiller 2 was $26^{\circ} \mathrm{C}$. Thus, based on the defect 
quantity analysis, the comparison for the setting was be made. The experiment for both settings were ran for 10 shots. Based on the comparison, the best setting based on the experimental layout and the current setting was used in the company. Fig. 5 show that the defect quantity for optimum sets. The optimum setting graph show $21 \%$ reduction rate from $56 \%$ to $35 \%$ of defect quantity.

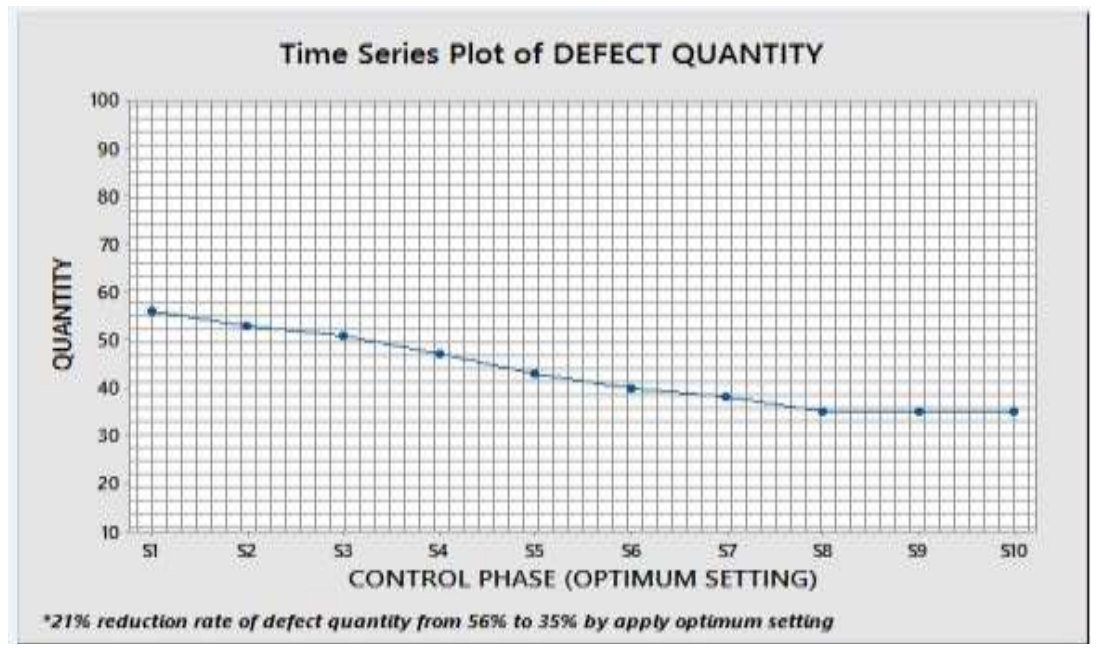

Fig. 5. Time series plot of defect quantity for optimum setting

\subsection{Validation of Best Setting}

For the validation of best setting predicted for the experiment, the production ran for 30 shots. For the validation, the total pieces used were 480 pieces and the analysis was also made to find the defect quantity from the validation run. The defect quantity from the validation testing was in the range of 160 per 480 pieces. The conclusion that could be made from the validation was, the best setting for the experiment gave the less quantity of defect differed from the quantity defect using the setting applied by the company.

Calculation for validation

$$
\begin{aligned}
& \text { Error } \%=[\mid \text { prediction-experiment } \mid / \text { prediction }] \times 100 \quad \text { (Eq.1) } \\
& =[|58-57| / 58] \times 100 \\
& =1.72 \%
\end{aligned}
$$

\section{Conclusions}

In conclusion, the Design of Experiment by using the factorial design approach showed improvement in the reduction of defect quantity. In this study, there were several statistical analysis or regression models investigated. $\mathrm{R}_{2}$ and $\mathrm{p}$-value statistics were used to identify the best models or the optimum setting for the experiment. ANOVA was used to determine the most significant parameter in this study and the estimated coefficients for defect quantity could be calculated using data in encoded units. Moreover, from the ANOVA, all the main effects showed the three parameters which were Mould hot runner temperature and Water cooling chiller temperature $1 \& 2$ were significant. There was a significant improvement in the reduction of the quantity of defect in their production. As for future 
research, it is recommended that further analysis on the response using surface method and design, such analysis if conducted in a more advanced way could lead to more improvement in production quality. Furthermore, it is also recommended that the analysis includes classifying the defects quantity into types of defects. This will help to find out specifically the kind of defects caused by each cavity,

\section{Acknowledgments}

The authors acknowledge Ministry of Higher Education for funded PPRN Grant Vot A049 .and Faculty of Mechanical and Manufacturing Engineering (UTHM) for facilities. Special thanks to those who contributed to this project directly or indirectly.

\section{References}

1. G. Potsch and W. Michaeli "Injection Moulding : An Introduction”, Munich : Hanser Publication, (1995)

2. Pei Jen Wang and Jui Ming Liang. Journal Of Injection Moulding Technology 6(1): 58 $-70,(2002)$

3. Ottmar Brandau .Bottles, Preforms and Closures. 2nd Ed. USA: Plastic Design Library. (2012)

4. Kenplas Industry Limited, Hangzhou Kenplas Machinery Ltd .PET Preform Making, PET Bottle Making. Hangzhou (2016.)

5. D.V.Rosorto, M.G Rosato, "Injection Moulding Handbook" Massachusetts: Kluwer Academic Publisher, (2000)

6. R. Konda, K.P. Rajurkar, R.R. Bishu, A. Guha and M. Parson. Design Of Experiments To Study And Optimize Process Performance. International Journal Of Quality \& Reliability Management. 16 (1): 56 - 71(1999)

7. F.Shi, Z.L Lou, J.G. Lu and Y.Q Zhang "Optimization Of Plastic Injection Moulding Process With Soft Computing : Int .J. Adv Manufacturing Tech. Vol 21, pp 656-661 (2003)

8. D.V.Rosorto, N.R Schott and M.G Rosato, "Plastic Engineering, Manufacturing And Data Handbook" Boston :Springer, pp 406-407 (2001)

9. P. Fletcher and D. Thesis, "Founding and requirements of starting a plastics product factory," (2013)

10. SACMI Group Article, Watermarks, Shrinkage \& Surface Defects : The „Invisiblee Faults On PET Preforms. (2015)

11. Douglas C. Montgomery, Design And Analysis Of Experiment. Eight Edition. Arizona State University. (2013)

12. Wen-Chin Chen, Manh-Hung Nguyen, Wen-Hsin Chiu, Te-Ning Chen, Pei-Hao Tai "Optimization of the plastic injection molding process using the Taguchi method, RSM, and hybrid GA-PSO": Int. J. Adv. Manuf. Technology, Springer-Verlag , (2015) 